\title{
Metal Powder for Additive Manufacturing
}

\author{
M. QIAN ${ }^{1,2}$ \\ 1.-School of Aerospace, Mechanical and Manufacturing Engineering, Centre for Additive \\ Manufacturing, RMIT University, Melbourne, VIC 3001, Australia. 2.—e-mail: ma.qian@rmit. \\ edu.au
}

Metal additive manufacturing (AM) processes are poised to transform the metal manufacturing industry, particularly in those areas where conventional manufacturing reaches its limitations in terms of both design freedom and manufacturing capabilities. Many metal AM systems are available today, including the powder-bed, powder-fed, and wire-fed processes based on laser, electron beam or plasma melting. At the same time, the variety of metal powder materials suitable for AM continues to expand. Currently there are 29 common metal powder materials available for AM, including stainless steels, aluminum, nickel, cobalt-chrome, and titanium alloys. ${ }^{1}$ The articles selected for this focus topic of JOM under Metal Powder for Additive Manufacturing are largely focused on metal powder for powder-bed fusion AM processes.

The importance of metal powder characteristics in the powder-bed fusion AM processes has become increasingly recognized. How the powder flows and packs, can have a significant impact on powder bed formation, and hence the development of melt pools and microscopic homogeneity. Excessive variations in powder characteristics can lead to nonuniform layering, inconsistent bulk density, increased defects, undesired mechanical properties, and poor surface finish. As a result, it is essential to be able to identify the various powder characteristics that can ensure consistent and reliable performance, particularly when a lower cost, less spherical powder is intended for AM.

In the first article, Slotwinski and Garboczi discuss the metrology needs for metal AM powders. The authors provide an informative overview of the current technical challenges and needs in characterizing metal powders for AM, processes based on laser, electron beam or plasma melting including recent efforts to standardize characterization

Ma Qian is the guest editor for the Powder Materials Committee the TMS Materials Processing and Manufacturing Division (MPMD), and coordinator of the topic Metal Powder for Additive Manufacturing (3D Printing) in this issue. methods in the ASTM International (ASTM) and the International Organization for Standardization (ISO), such as the recently released ASTM F3049, Standard Guide for Characterizing Properties of Metal Powders Used for Additive Manufacturing Processes.

In the second article in this compilation, Clayton et al. show the necessity of appropriate metal powder characterization for AM through four case studies, and the inability of conventional characterization techniques to detect the subtle differences. These four case studies deal with (I) quantifying batch-to-batch variation in feedstocks, (II) the influence of different suppliers and manufacturing methods, (III) the effect of additives on feedstock properties, and (IV) process-relevant differences between fresh and used feedstocks. These are all important issues in metal AM.

The third article by Strondl and co-workers is concerned with the characterization and control of powder properties for AM. The authors discuss the combined use of powder rheology and dynamic image analysis to characterize metal powders for AM. This study adds another useful case study to metal powder characterization for AM.

In the fourth article in this sequence, Tang et al. report on the effect of powder reuse times on the AM of Ti-6Al-4V using an Arcam EBM A2 system (Arcam AB, Mölndal, Sweden). Parts manufacturers are always both quality- and cost-conscious. In metal AM processes, the powder reuse times directly affect the affordability of the additively manufactured parts. Hence, it is necessary to identify the effect of powder reuse times on the AM process and the mechanical properties of the alloy thus fabricated. The powder composition, particle size distribution, apparent density, tap density, flowability, and particle morphology were studied as a function of powder reuse times and compared with respective properties of the virgin Arcam Ti-6Al-4V powder. Detailed tensile mechanical property data were produced from samples fabricated using Ti-6Al-4V powder that had been reused 16 times. The samples 
showed highly consistent tensile properties, irrespective of their locations in the powder bed.

In the context of the AM of titanium, the high cost of titanium metal powder used for AM has been a concern for the wider applications of Ti AM. Lowering the cost of the feedstock titanium metal powder is thus desired. In the fifth article by Sun et al. the authors discuss the use of a Commonwealth Scientific and Industrial Research Organisation (CSIRO) proprietary technique to manipulate a novel titanium powder precursor. The manipulated titanium powder was characterized using various techniques, including the utilization of an external powder bed system, which contains an identical powder feed and raking system to that used in an Arcam A1 EBM machine. The manipulated low-cost titanium powder in the size range of 75-106 $\mu \mathrm{m}$ was found to behave very similarly to reused Arcam Ti-6Al-4V powder in such an external powder bed system.

In the sixth and final article in this collection, Tong et al. provide a concise summary of recent efforts to produce fine spherical high-niobium-containing TiAl alloy powders. A compact process was proposed and demonstrated by the authors for the preparation of microfine spherical high-niobiumcontaining TiAl alloy powders.

In summary, this selection of articles highlights different aspects of metal powder feedstock materials for AM and offers a snapshot of the current activities in this area of research. To download any of the papers, follow the URL: http://link.springer. com/journal/11837/67/3/page/1 to the table of contents page for the March 2015 issue (Vol. 67, No. 3).

- "Metrology Needs for Metal Additive Manufacturing Powders," by J. Slotwinski and E. Garboczi

- "The Application of Powder Rheology in Additive Manufacturing," by J. Clayton, D. MillingtonSmith, and B. Armstrong

- "Characterization and Control of Powder Properties for Additive Manufacturing," by A. Strondl, O. Lyckfeldt, H. Brodin, and U. Ackelid

- "Effect of Powder Reuse Tong et al. Times on Additive Manufacturing of Ti-6Al-4V Selective Electron Beam Melting," by H.P. Tang, M. Qian, N. Liu, X.Z. Zhang, G.Y. Yang, and J. Wang

- "Manipulation and Characterization of a Novel Titanium Powder Precursor for Additive Manufacturing Applications," by Y.Y. Sun, S. Gulizia, C.H. Oh, C. Doblin, Y.F. Yang, and M. Qian

- "Compact Process for the Preparation of Microfine Spherical High-Niobium-Containing TiAl Alloy Powders," by J.B. Tong, X. Lu, C.C. Liu, L.N. Wang, and X.H. Qu

\section{REFERENCE}

1. J.F. Isaza and P.C. Aumund-Kopp, Powder. Metall. Rev. 3, $41(2014)$ 